\title{
Article \\ Selective Hydrogenation of Phenol to Cyclohexanol over Ni/CNT in the Absence of External Hydrogen
}

\author{
Changzhou Chen ${ }^{1,2}$, Peng Liu ${ }^{1,2}$, Minghao Zhou ${ }^{1,2,3, *}$, Brajendra K. Sharma ${ }^{3, *} \mathbb{C}$ and \\ Jianchun Jiang ${ }^{1,2, *}$
}

1 Institute of Chemical Industry of Forest Products, Chinese Academy of Forestry, Key Laboratory of Biomass Energy and Material, Jiangsu Province, National Engineering Laboratory for Biomass Chemical Utilization, Key and Open Laboratory on Forest Chemical Engineering, SFA, Nanjing 210042, China; changzhou_chen@163.com (C.C.); liupengnl@163.com (P.L.)

2 Co-Innovation Center of Efficient Processing and Utilization of Forest Resources, Nanjing Forestry University, Nanjing 210037, China

3 Illinois Sustainable Technology Center, Prairie Research Institute, one Hazelwood Dr., Champaign, University of Illinois at Urbana-Champaign, Champaign, IL 61820, USA

* Correspondence: zmhzyk19871120@163.com (M.Z.); bksharma@illinois.edu (B.K.S.); jiangjc@icifp.cn (J.J.)

Received: 7 January 2020; Accepted: 11 February 2020; Published: 14 February 2020

\begin{abstract}
Transfer hydrogenation is a novel and efficient method to realize the hydrogenation in different chemical reactions and exploring a simple heterogeneous catalyst with high activity is crucial. Ni/CNT was synthesized through a traditional impregnation method, and the detailed physicochemical properties were performed by means of XRD, TEM, XPS, BET, and ICP analysis. Through the screening of loading amounts, solvents, reaction temperature, and reaction time, $20 \% \mathrm{Ni} / \mathrm{CNT}$ achieves an almost complete conversion of phenol after $60 \mathrm{~min}$ at $220^{\circ} \mathrm{C}$ in the absence of external hydrogen. Furthermore, the catalytic system is carried out on a variety of phenol derivatives for the generation of corresponding cyclohexanols with good to excellent results. The mechanism suggests that the hydrogenation of phenol to cyclohexanone is the first step, while the hydrogenation of cyclohexanone for the generation of cyclohexanol takes place in a successive step. Moreover, $\mathrm{Ni} / \mathrm{CNT}$ catalyst can be magnetically recovered and reused in the next test for succeeding four times.
\end{abstract}

Keywords: phenol; hydrogenation; Ni/CNT; cyclohexanol; transfer hydrogenation

\section{Introduction}

Cyclohexanol is an important chemical raw materials, for example, it could be used as the main intermediate for the production of adipic acid, hexamethylene diamine, cyclohexanone, and caprolactam, or as an excellent solvent for rubber, resin, nitro fiber, and metal soap [1-5]. Except for this, its downstream product, cyclohexane, can also be converted into various useful chemicals [6-8]. Hence, the production of cyclohexanol has attracted increasing attention, both in industry and in the laboratory, recently. In the past several years, tremendous efforts have been devoted to the hydrogenation of phenol for the generation of cyclohexanol. The main pathways can be classified into two groups, gaseous [9] and liquid phase [10]. In the gaseous phase, a variety of supported noble metals, such as Pd [11,12], Pt [13,14], Ru [15,16], Rh [17,18], have been reported to be effective in the hydrogenation system. For example, Wang et al. reported a hierarchically porous ZSM-5 zeolite with micropore and b-axis-aligned mesopore-supported Ru nanoparticles (Ru/HZSM-5-OM), which were highly effective for the hydrogenation of both phenol and its derivatives to the corresponding cyclohexane [15]. However, elevated temperature and high pressure of hydrogen $\left(150^{\circ} \mathrm{C}, 4 \mathrm{MPa}\right)$ were required, and carbonaceous deposits in the process would result in the deactivation of catalyst. In the liquid phase, although 
the hydrogenation process could be performed under a relatively lower temperature [19], the main shortcoming of recent hydrogenation systems is that they could not avoid the presence of hydrogen [20]. For instance, $\mathrm{Li}$ et al. developed a series of Pd@FDU-N catalysts for the hydrogenation of phenol in the presence of $0.1 \mathrm{MPa} \mathrm{H}_{2}$ [21]. Therefore, the exploration of a cheap and effective catalyst for the hydrogenation of phenol in the absence of hydrogen is essential. Catalytic transfer hydrogenation (CTH) has been regarded as a good alternative to avoid the application of high-pressure hydrogen [22-25]. Galkin et al. reported that $\mathrm{Pd} / \mathrm{C}$ could catalyze transfer hydrogenolysis of $\beta-\mathrm{O}-4$ model compound in lignin employing formic acid as a hydrogen-donor for the generation of acetophenone and phenol derivatives [22]. Paone et al. reported the transfer hydrogenolysis of $\alpha-\mathrm{O}-4$ model compound in lignin conducted on $\mathrm{Pd} / \mathrm{Fe}_{3} \mathrm{O}_{4}$ under $240{ }^{\circ} \mathrm{C}$ [23]. Wu et al. found that $\mathrm{Ru} / \mathrm{C}$ could efficiently catalyze the cleavage of the 4-O-5 aromatic ether bond in a variety of lignin-derived compounds through the transfer hydrogenolytic pathway using isopropanol as the hydrogen-donor solvent [24]. Despite those achievements for the transfer hydrogenolytic transformation of biomass to value-added chemicals, the catalytic hydrogenation without the use of external hydrogen remains a great challenge [25,26].

Carbon nanotubes (CNT) are interesting materials for carrying out chemical reactions in confined spaces, and several organic reactions have been carried out [27-29] inside the nanotubes. In this work, CNT supported nickel catalyst was introduced into the hydrogenation of phenol for the generation of cyclohexanol via a transfer hydrogenolytic route. Through the screening of loading amounts, solvents, temperature and time, herein we reported a mild reaction condition $\left(20 \% \mathrm{Ni} / \mathrm{CNT}\right.$, $\mathrm{PrOH}, 220^{\circ} \mathrm{C}$ and $60 \mathrm{~min}$ ) for the hydrogenation of phenol to cyclohexanol. A variety of phenol derivatives were also conducted to verify the high efficiency of this catalytic reaction system. The possible reaction mechanism was finally investigated as well. The detailed physicochemical properties were investigated by means of XRD, TEM, XPS, BET, and ICP analysis.

\section{Experimental}

Materials: CNT was purchased from Aladdin Industrial Inc. Shanghai, China and pre-treated in $\mathrm{HNO}_{3}$ before use $[27,28]$. $\mathrm{Ni}\left(\mathrm{NO}_{3}\right)_{2} \cdot 6 \mathrm{H}_{2} \mathrm{O}$ was provided by Aladdin Industrial Inc. Shanghai, China. Phenol and other derivatives were obtained from tansoole.com. All chemicals were obtained from commercial sources and used without further purification.

General procedure for Ni/CNT catalyzed phenol: In one typical catalytic reaction process, 500 $\mathrm{mg}$ of phenol and other derivatives, $50 \mathrm{mg}$ of Ni/CNT catalyst, and $10 \mathrm{~mL}$ isopropanol were placed in a $25 \mathrm{~mL}$ stainless steel reactor. After being sealed, the catalytic reaction was stirred at desired temperature for desired time. The reactor was naturally cooled to room temperature after the reaction. The mixture solution was filtered to collect the catalyst and the filtrate was analyzed by the Gas Chromatograph/Mass Spectrometer (GC/MS, Agilent 7890) utilizing n-dodecane as an internal standard. The collected catalyst was washed with isopropanol three times and dried at $105^{\circ} \mathrm{C}$ for the next test under the optimal reaction conditions. The conversion and product yields in the liquid phase were calculated according to the following formula, respectively:

$$
\begin{gathered}
\text { Conversion }=\frac{\text { mole of reacted substrate }}{\text { total mole of substrate feed }} \times 100 \% \\
\text { Yield of cyclohexanone }=\frac{\text { mole of cyclohexanone }}{\text { total mole of substrate feed }} \times 100 \% \\
\text { Yield of cyclohexanol }=\frac{\text { mole of cyclohexanol }}{\text { total mole of substrate feed }} \times 100 \%
\end{gathered}
$$

Catalyst preparation: $\mathrm{Ni} / \mathrm{CNT}$ was prepared by an impregnation method. In one typical process of $20 \% \mathrm{Ni} / \mathrm{CNT}$ catalyst, $\mathrm{Ni}\left(\mathrm{NO}_{3}\right)_{2} \cdot 6 \mathrm{H}_{2} \mathrm{O}(0.2 \mathrm{~g})$ was dissolved in $30 \mathrm{~mL}$ of deionized water. Then, CNT $(2.0 \mathrm{~g})$ was added to the above solution and stirred for $24 \mathrm{~h}$ until a uniform dispersion. The obtained suspension was dried for $12 \mathrm{~h}$ at $105^{\circ} \mathrm{C}$ in the oven. Subsequently, the obtained black 
solid was calcined at $500{ }^{\circ} \mathrm{C}$ for $2 \mathrm{~h}$ in the muffle furnace, and finally reduced in a tube furnace under hydrogen atmosphere at $500^{\circ} \mathrm{C}$ for $2 \mathrm{~h}$. The preparation of Fe/CNT, Co/CNT, Mo/CNT was the same as Ni/CNT.

Catalyst characterization: Powder X-ray diffraction (XRD) was examined on a Bruker D8 Advance X-ray powder diffractometer. Transmission electron microscopy (TEM) images were tested using a TEM Tecnai G2 20. The X-ray photoelectron spectroscopy (XPS) was carried out on an ESCALAB-250 (Thermo-VG Scientific, USA) spectrometer with $\mathrm{Al} \mathrm{K} \alpha(1486.6 \mathrm{eV})$ irradiation source. The textural properties of the $\mathrm{Ni} / \mathrm{CNT}$ catalyst were tested by $\mathrm{N}_{2}$ adsorption-desorption isotherms using a COULTER SA 3100 analyzer, and the Brunauer-Emmett-Teller (BET) surface area was evaluated by the N 2 adsorption-desorption isotherms.

\subsection{Catalyst Characterization}

Figure 1 shows the XRD patterns of two different samples, including solo CNT, and the optimal catalyst in the system for the hydrogenation of phenol. The peak at $26.5^{\circ}$ could be assigned to the diffraction peaks of the (002) planes of the graphite-like tube-wall of the CNT [30-32]. Apart from the CNT feature, the presence of metallic Ni in the reduced $20 \% \mathrm{Ni} / \mathrm{CNT}$ catalyst was clearly revealed. As could be clearly seen from the XRD results, only one kind of Ni-based phase was observed for $\mathrm{Ni} / \mathrm{CNT}$ catalyst. Peaks at $44.5^{\circ}, 51.9^{\circ}$, and $76.4^{\circ}$ could be assigned to the diffraction of the (111), (200), and (220) planes of metallic Ni [27], indicating that only metallic nickel species were observed in $\mathrm{Ni} / \mathrm{CNT}$ catalyst.

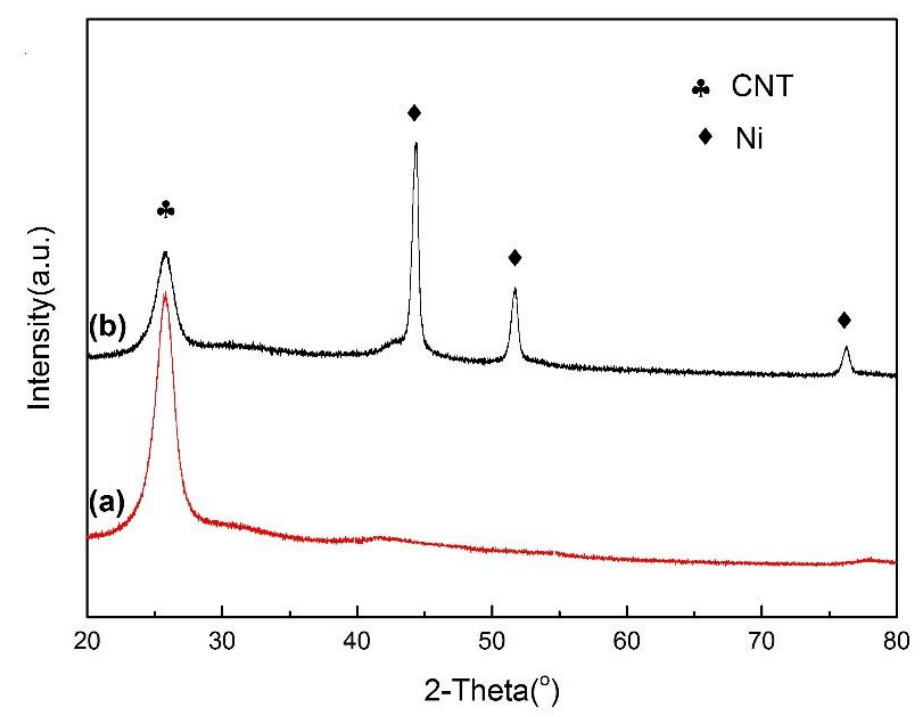

Figure 1. Characterization of the $20 \% \mathrm{Ni} / \mathrm{CNT}$ catalyst. (a) XRD pattern of CNT, (b) XRD pattern of $20 \% \mathrm{Ni} / \mathrm{CNT}$.

XPS detection was carried out to analyze the composition of prepared $20 \% \mathrm{Ni} / \mathrm{CNT}$. The absorption peaks were identified for $\mathrm{C}, \mathrm{O}$, and $\mathrm{Ni}$. As for the presence of oxygen element in Figure $2 \mathrm{~b}$, perhaps it was due to the presence of oxygen-containing groups of CNT during the $\mathrm{HNO}_{3}$ pre-processing [30,31]. In addition, the oxidation of Ni/CNT catalyst before or during the XPS examination could also lead to the presence of oxygen element. The binding energies at 852.9 and $856.3 \mathrm{eV}$ were observed for $20 \%$ $\mathrm{Ni} / \mathrm{CNT}$ (Figure 2a), which corresponded to $\mathrm{Ni}^{0}(2 \mathrm{p} 3 / 2)$ and $\mathrm{Ni}^{2+}(2 \mathrm{p} 3 / 2)$, respectively. The binding energies at 872.3 and $874.8 \mathrm{eV}$ corresponded to the main lines of $\mathrm{Ni}^{0}(2 \mathrm{p} 1 / 2)$ and $\mathrm{Ni}^{2+}(2 \mathrm{p} 1 / 2)$. It could be found that part of metallic Ni was oxidized before or during the XPS testing, which contributed to the understanding of $\mathrm{Ni}^{2+}$ detection in the XPS spectra. 


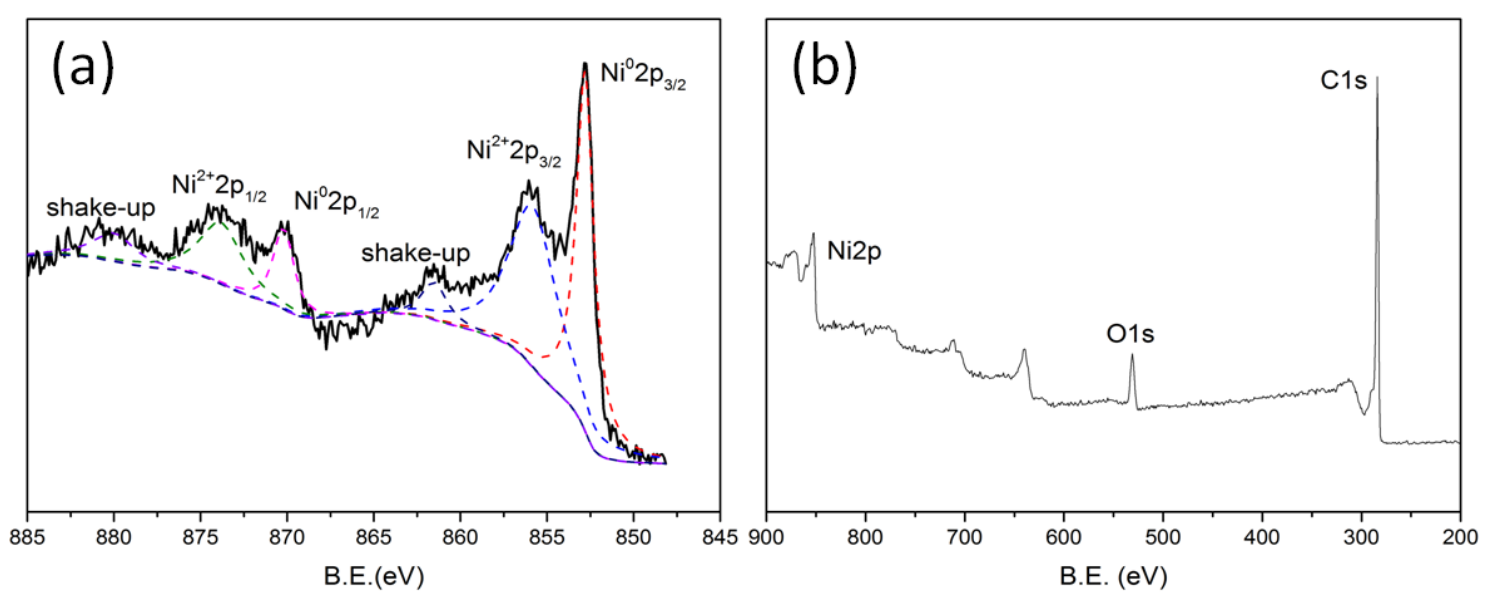

Figure 2. Characterization of the $20 \% \mathrm{Ni} / \mathrm{CNT}$ catalyst. (a) XPS of Ni 2p, (b) XPS pattern of 20\% Ni/CNT.

As can be seen in Figure 3, most of Ni particles displayed outside the CNT uniformly. However, the Ni particle size and its distribution varied from each other mainly owing to the loading amount of Ni on the surface of CNT. We selected $20 \% \mathrm{Ni} / \mathrm{CNT}$ catalyst as an example. The histogram of $20 \%$ $\mathrm{Ni} / \mathrm{CNT}$ in given in Figure 3a, in which the mean size was $14.0 \mathrm{~nm}$. Taken together, nanoparticle Ni on the surface of CNT performed an excellent activity in the hydrogenation of phenol under our reaction system.
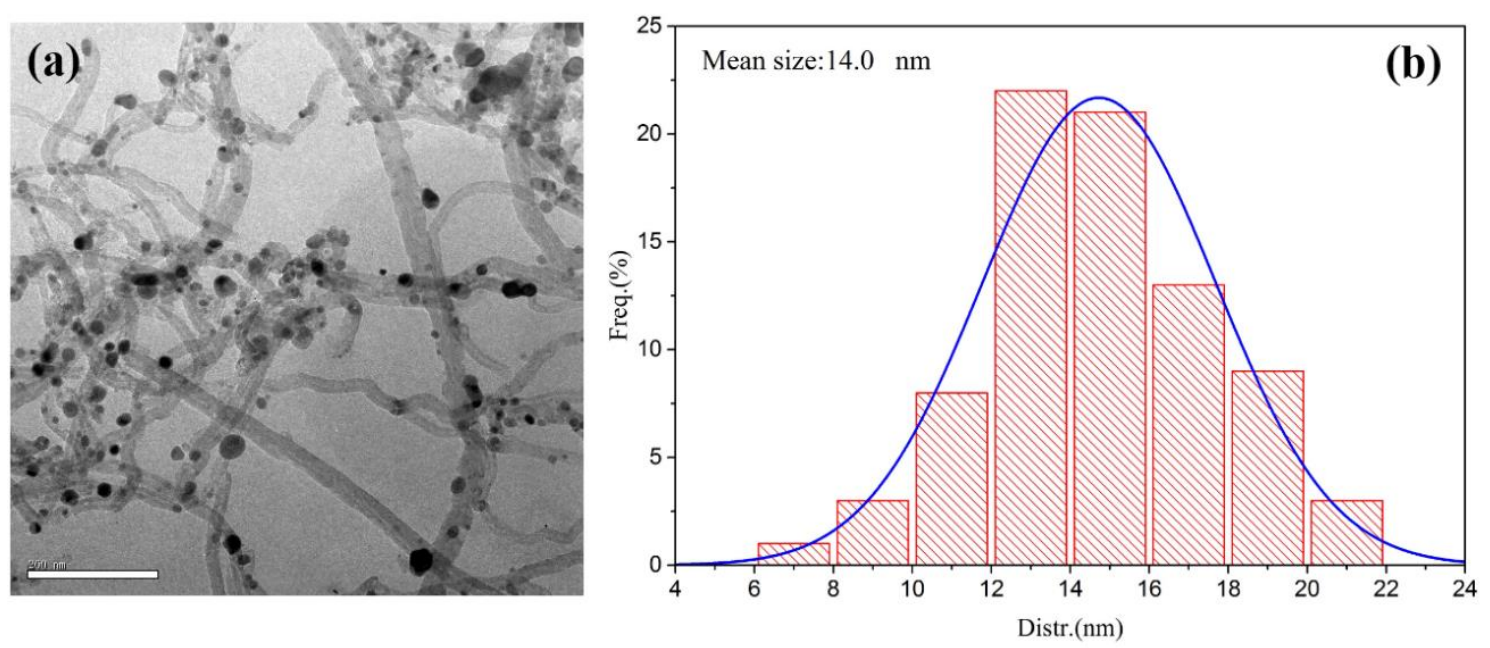

Figure 3. Characterization of the $20 \% \mathrm{Ni} / \mathrm{CNT}$ catalyst. (a) TEM image of $20 \% \mathrm{Ni} / \mathrm{CNT}$, (b) Distribution of Ni particles.

Table 1 show the chemical and physical properties for the different ratios of Ni/CNT catalysts, including the Ni loading amounts, BET surface area, and average Ni-particle size. The ICP results prove that the metal loading amounts were in great accordance with the theoretical calculating value with the preparation of the catalysts. The BET surface area of $5 \% \mathrm{Ni} / \mathrm{CNT}$ catalyst was much larger than $25 \%$ $\mathrm{Ni} / \mathrm{CNT}$ (range from $149.3 \mathrm{~m}^{2} / \mathrm{g}$ to $120.5 \mathrm{~m}^{2} / \mathrm{g}$ ), suggesting that Ni particles could be better dispersed on the surface of CNT. Owing to the different loading amounts of Ni on the CNT, the average particle size of Ni/CNT with different metal amounts ranged from 12.1 to $15.6 \mathrm{~nm}$ (estimated from XRD in Table 1). It proved that excessive metal loading on CNT could inevitably lead to metal agglomeration, resulting in an increase of the metal particle size [32]. The TEM also gave the same results on the distribution of Ni particles (Table 1). Hence, these changes in catalyst properties would directly influence the catalytic activity in the hydrogenation of phenol, which will be discussed in detail in the following experiments. 
Table 1. Chemical and physical properties of CNT-supported Ni catalysts.

\begin{tabular}{|c|c|c|c|c|}
\hline \multirow{2}{*}{ Catalysts } & Composition (wt.\%) ${ }^{a}$ & \multirow{2}{*}{$\begin{array}{l}S_{\text {BET }} b \\
\left(\mathrm{~m}^{2} / g\right)\end{array}$} & \multirow{2}{*}{$\begin{array}{l}\text { Average Metal } \\
\text { Size }^{c}(\mathrm{~nm})\end{array}$} & \multirow{2}{*}{$\begin{array}{l}\text { Average Metal } \\
\text { Size }^{\mathrm{d}}(\mathrm{nm})\end{array}$} \\
\hline & $\mathbf{N i}$ & & & \\
\hline CNT & / & 180.6 & / & / \\
\hline $5 \% \mathrm{Ni} / \mathrm{CNT}$ & 4.32 & 149.3 & 12.1 & 12.8 \\
\hline $10 \% \mathrm{Ni} / \mathrm{CNT}$ & 10.55 & 145.6 & 12.6 & 13.1 \\
\hline $15 \% \mathrm{Ni} / \mathrm{CNT}$ & 14.66 & 135.8 & 12.8 & 13.5 \\
\hline $20 \% \mathrm{Ni} / \mathrm{CNT}$ & 19.68 & 132.4 & 13.1 & 14.0 \\
\hline $25 \% \mathrm{Ni} / \mathrm{CNT}$ & 24.09 & 120.5 & 15.6 & 16.5 \\
\hline
\end{tabular}

a_measured by ICP analysis, ${ }^{b}$-evaluated from $\mathrm{N}_{2}$ adsorption-desorption isotherms, c — estimated by XRD, $\mathrm{d}$-measured by TEM.

\subsection{Activity of Various Catalysts for the Hydrogenation of Phenol}

First of all, hydrogenation of phenol was chosen as a typical model reaction to explore the catalytic performance over a variety of catalysts (Table 2). When carried out without any catalysts in the hydrogenolytic system, the reaction failed to transform phenol to cyclohexanol (Table 2, entry 1). Meanwhile, solo CNT also showed a poor activity under our reaction condition (Table 2, entry 2), indicating that CNT only served as a support, and showed no catalytic effect in the catalytic process. Then, we tried different catalysts for the transformation of phenol, including $10 \% \mathrm{Fe} / \mathrm{CNT}, 10 \% \mathrm{Co} / \mathrm{CNT}$, $10 \% \mathrm{Mo} / \mathrm{CNT}$ and $10 \% \mathrm{Ni} / \mathrm{CNT}$ (Table 2, entries 3-5 and entry 7 ). It was surprising to discover that the supported $\mathrm{Ni}$ catalyst exhibited good performance in the hydrogenation of phenol to generate cyclohexanol, indicating that the substrate phenol adsorbed on the metal surface prior to the reaction decreased the activation barrier of hydrogenation reaction [33]. The catalytic activity could be sorted as follows: $10 \% \mathrm{Ni} / \mathrm{CNT}>10 \% \mathrm{Co} / \mathrm{CNT}>10 \% \mathrm{Mo} / \mathrm{CNT}>10 \% \mathrm{Fe} / \mathrm{CNT}$. However, the loading amount of Ni on the surface of CNT could also affect the efficiency of the hydrogenolytic process. It could be clearly seen in Table 2 that the conversion increased with the increased loading amount of $\mathrm{Ni}$ (from $5 \%$ to $25 \%$ ), and the trend of the cyclohexanol yield showed the same result. Meanwhile, we found that the yield of cyclohexanol reached $95 \%$ when $20 \% \mathrm{Ni} / \mathrm{CNT}$ was used in our hydrogenolytic system (Table 2, entries 6-10). On the base of the results above, $20 \% \mathrm{Ni} / \mathrm{CNT}$ was chosen as the most suitable catalyst for the subsequent exploration.

Table 2. Optimization of catalysts for the hydrogenation of phenol ${ }^{\text {a }}$.

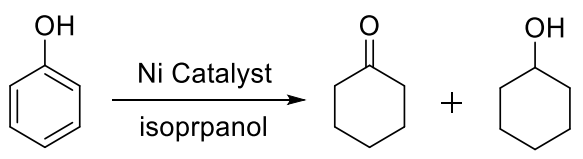

$1 \mathrm{a}$

2a $3 \mathbf{a}$

\begin{tabular}{cccccc}
\hline \multirow{2}{*}{ Entry } & Catalyst & \multirow{2}{*}{$\begin{array}{c}\text { T. }\left({ }^{\circ} \mathbf{C}\right) / \\
\text { t.(h) }\end{array}$} & Con. (\%) & \multicolumn{2}{c}{ Yield (\%) ${ }^{\mathbf{b}}$} \\
\cline { 5 - 6 } & & & & $\mathbf{2 a}$ & 3a \\
\hline 1 & none & $180 / 4$ & 0 & 0 & 0 \\
2 & $\mathrm{CNT}$ & $180 / 4$ & 0 & 0 & \\
3 & $10 \% \mathrm{Fe} / \mathrm{CNT}$ & $180 / 4$ & 8 & 2 & 0 \\
4 & $10 \% \mathrm{Co} / \mathrm{CNT}$ & $180 / 4$ & 48 & 5 & 5 \\
5 & $10 \% \mathrm{Mo} / \mathrm{CNT}$ & $180 / 4$ & 27 & 4 & 22 \\
6 & $5 \% \mathrm{Ni} / \mathrm{CNT}$ & $180 / 4$ & 73 & 3 & 66 \\
7 & $10 \% \mathrm{Ni} / \mathrm{CNT}$ & $180 / 4$ & 81 & 4 & 68 \\
8 & $15 \% \mathrm{Ni} / \mathrm{CNT}$ & $180 / 4$ & 95 & 3 & 88 \\
9 & $20 \% \mathrm{Ni} / \mathrm{CNT}$ & $180 / 4$ & 100 & 2 & 95 \\
10 & $25 \% \mathrm{Ni} / \mathrm{CNT}$ & $180 / 4$ & 100 & 2 & 94 \\
\hline
\end{tabular}

a Reaction conditions: 1a $(500 \mathrm{mg})$, catalyst $(50 \mathrm{mg})$, Isopropanol $(10 \mathrm{~mL}) .{ }^{\mathrm{b}}$ The conversion and yield were determined by GC/MS with n-dodecane as the internal standard. 


\subsection{Influence of Hydrogen-Donor Solvents}

Alcohol, as an excellent hydrogen-donor solvent, plays an important role in the catalytic transfer hydrogenolytic process. Therefore, we selected three most common alcohols in our catalytic system. Unfortunately, methanol and ethanol failed the transformation of phenol to cyclohexanol (Table 3, entries 2-3). $\mathrm{H}_{2} \mathrm{O}$ was considered as a green and environmentally friendly solvent, and always applied in various chemical reactions. However, $20 \% \mathrm{Ni} / \mathrm{CNT}$ catalyst showed a poor activity in the hydrogenation of phenol in aqueous media (Table 3, entry 4). When isopropanol was utilized in our catalytic system, a satisfactory result was achieved that cyclohexanol was obtained in the yield of 95\% (Table 3, entry 1). Therefore, isopropanol was the most efficient hydrogen-donor solvent for the transformation of phenol to cyclohexanol.

Table 3. Optimization of solvents for the hydrogenation of phenol ${ }^{\mathrm{a}}$.

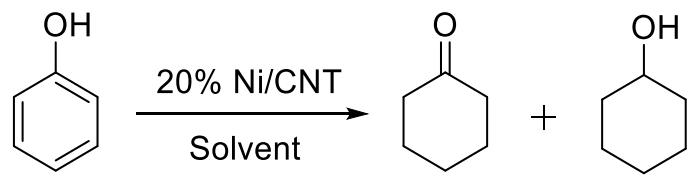

$1 \mathrm{a}$

$2 a$

$3 \mathbf{a}$

\begin{tabular}{cccccc}
\hline \multirow{2}{*}{ Entry } & Solvent & \multirow{2}{*}{ T. $\left({ }^{\circ} \mathbf{C}\right) /$} & Con. (\%) & \multicolumn{2}{c}{ Yield (\%) $\mathbf{b}$} \\
\cline { 5 - 6 } & t. $(\mathbf{h})$ & & $\mathbf{2 a}$ & $\mathbf{3 a}$ \\
\hline 1 & isopropanol & $180 / 4$ & 100 & 2 & 95 \\
2 & methanol & $180 / 4$ & 15 & 3 & 6 \\
3 & ethanol & $180 / 4$ & 13 & 2 & 5 \\
4 & $\mathrm{H}_{2} \mathrm{O}$ & $180 / 4$ & 5 & 0 & 0 \\
\hline
\end{tabular}

a Reaction conditions: 1a $(500 \mathrm{mg}), 20 \% \mathrm{Ni} / \mathrm{CNT}(50 \mathrm{mg})$, Solvent $(10 \mathrm{~mL}) .{ }^{\mathrm{b}}$ The conversion and yield were determined by GC/MS with n-dodecane as the internal standard.

\subsection{Influence of Reaction Temperature and Reaction Time}

In addition, reaction temperature and reaction time were important key factors for the transformation of phenol (Figure 4). As shown in Figure 4a, the conversion of phenol progressively increased when the reaction temperature increased from 160 to $220^{\circ} \mathrm{C}$, and phenol could almost totally transfer to cyclohexanol at $220{ }^{\circ} \mathrm{C}$ with a reaction time of $60 \mathrm{~min}$. In the catalytic process, the dominant products were cyclohexanol, with a small amount of cyclohexanone detected in the GC/MS. As the temperature continued to rise, the yield of cyclohexanol kept around $95 \%$. Subsequently, it could be found that the conversion of phenol increased with the prolonging of the reaction time (Figure $4 b$ ), and the phenol was completely consumed in only $60 \mathrm{~min}$ at $220^{\circ} \mathrm{C}$. With the prolonged reaction time, the yield of cyclohexanol increased when the reaction time increased from 20 to $60 \mathrm{~min}$. When the reaction time exceeded $60 \mathrm{~min}$, the conversion of phenol achieved $100 \%$, and the yield of cyclohexanol kept at the highest point. Through the screening of temperature and time of the hydrogenation of phenol, the optimal temperature and time could be summarized as $220^{\circ} \mathrm{C}$ and $60 \mathrm{~min}$, respectively. 

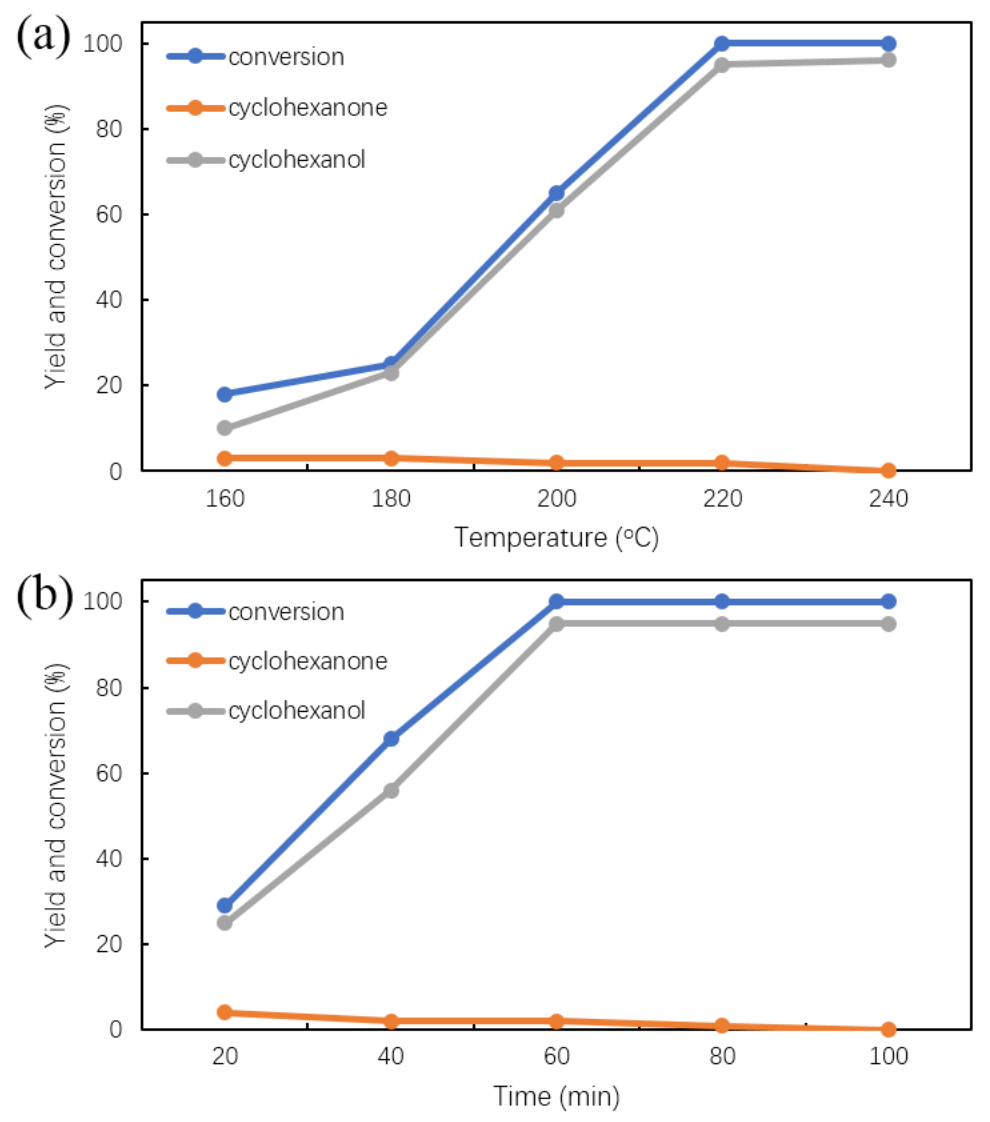

Figure 4. Influence of reaction temperature (a) and time (b) on the hydrogenation of phenol. Reaction conditions: Phenol (500 mg), 20\% Ni/CNT (50 mg), isopropanol (10 mL); reaction time, $60 \mathrm{~min}$ (for a); reaction temperature, $220^{\circ} \mathrm{C}$ (for b).

\subsection{Scope of the Substrates}

Encouraged by the perfect performance of the efficient hydrogenation of phenol, a variety of phenol derivatives were tested on $20 \% \mathrm{Ni} / \mathrm{CNT}$. As shown in Table 4 , phenol could be completely transformed to afford the corresponding cyclohexanol in a yield of $95 \%$ without additional hydrogen under the optimal reaction condition (Table 4, entry 1). Methylphenol derivatives gave methylcyclohexanols with a poor conversion and yield under $220^{\circ} \mathrm{C}$ at a reaction time of $60 \mathrm{~min}$. Therefore, we increased the temperature from $220^{\circ} \mathrm{C}$ to $240^{\circ} \mathrm{C}$. As excepted, methylphenol derivatives gave methylcyclohexanols with both perfect conversion and yield (Table 4, entries 2-4). Hydroxy substituted phenol could not achieve the CTH process under optimal conditions as well. Hence, $240{ }^{\circ} \mathrm{C}$ was employed in our reaction system and a 79\% yield of cyclohexane-1,2-diol was obtained in the reaction time of $60 \mathrm{~min}$ (Table 4, entries 5). Based on the relevant literature [34], the reason for the small decrease in the yields of corresponding cyclohexanol derivatives probably is the steric effect. Hence, the presence of substituent imposes a steric repulsion, which might lower the degree of adsorption and thus hydrogenation rate. Taken together, the transfer hydrogenation system was confirmed suitable for the hydrogenation of diverse phenol derivatives with good to excellent results. 
Table 4. Hydrogenation of phenol with substituted functional groups with $20 \% \mathrm{Ni} / \mathrm{CNT}$ in isopropanol ${ }^{\mathrm{a}}$.

\begin{tabular}{|c|c|c|c|c|}
\hline Entry & Substrate & $\mathrm{T}\left({ }^{\circ} \mathrm{C}\right) / \mathrm{t}$ (min) & Conversion (\%) & Yield of Product (\%) \\
\hline 1 & & $220 / 60$ & 100 & \\
\hline 2 & & $240 / 60$ & 89 & \\
\hline 3 & & $240 / 60$ & 90 & \\
\hline 4 & & $240 / 60$ & 85 & \\
\hline 5 & & $240 / 60$ & 88 & \\
\hline
\end{tabular}

${ }^{a}$ Reaction condition: $20 \% \mathrm{Ni} / \mathrm{CNT}(50 \mathrm{mg})$, substrate $(500 \mathrm{mg})$, solvent $(10 \mathrm{~mL})$.

\subsection{Mechanism Studies and the Recyclability of Ni/CNT}

The mechanism of the hydrogenation of phenol over $20 \% \mathrm{Ni} / \mathrm{CNT}$ was proposed in Figure 6. According to the time courses of phenol and products (Figure 4), the hydrogenation of phenol proceeded via cyclohexanone. In order to corroborate this, we investigated the activity of cyclohexanol and cyclohexanone in the process of transfer hydrogenation. When solo cyclohexanol was carried out in our catalytic system, no cyclohexanol was transformed into cyclohexanone (Figure 5a). The results above show the hydrogenation of phenol to cyclohexanol via cyclohexanone under a transfer hydrogenation process. It can be seen from Figure $5 \mathrm{~b}$ that, from the beginning of the process, the amount of cyclohexanone decreased and cyclohexanol was observed. Cyclohexanone was completely consumed after $30 \mathrm{~min}$ and cyclohexanol was achieved in high yield (over 90\%). Apart from this, acetone was also detected in the catalytic process. In Table 5, we could find that $95 \%$ of cyclohexanol, $2 \%$ of cyclohexanone, 5.8 equivalents of acetone and 33.6 equivalents of isopropanol were observed for each equivalent of phenol consumed, which suggested that the hydrogenation of phenol was a stoichiometric reaction and each phenol molecule needed six isopropanol molecules for the generation of cyclohexanol. Therefore, the detailed mechanism could be summarized in Figure 6. The molecule adsorption of isopropanol occurred on the catalyst surface to produce $\mathrm{H}^{*}$ and followed by phenol adsorption (i). Then, irreversible phenol hydrogenation took place for the generation of cyclohexanone, in which four equivalents of $\mathrm{H}^{*}$ were consumed (ii-iv). In the final step, two equivalents of $\mathrm{H}^{*}$ was employed in the catalytic process to transfer cyclohexanone to cyclohexanol (v). Based on the study above, we propose the mechanism in two steps: (1) Conversion of phenol to cyclohexanone over the Ni/CNT catalyst. (2) Transformation of cyclohexanol from cyclohexanone via keto-enol tautomerism.

Table 5. Distribution of products with $20 \% \mathrm{Ni} / \mathrm{CNT}$ in isopropanol.

\begin{tabular}{|c|c|c|c|c|c|c|}
\hline Catalyst & Temperature/Time & Conversion & & & & \\
\hline $\mathrm{Ni} / \mathrm{CNT}$ & $220^{\circ} \mathrm{C} / 60 \mathrm{~min}$ & $100 \%$ & $95 \%$ & $2 \%$ & 5.8 equiv & 33.6 equiv \\
\hline
\end{tabular}

Reaction condition:500 mg phenol (1.0 equiv), $50 \mathrm{mg} \mathrm{20 \%} \mathrm{Ni/CNT,10mL} \mathrm{isopropanol} \mathrm{(40.0} \mathrm{equiv).} \mathrm{Yield} \mathrm{was}$ determined by GC/MS with $\mathrm{n}$-dodecane as the internal standard. 

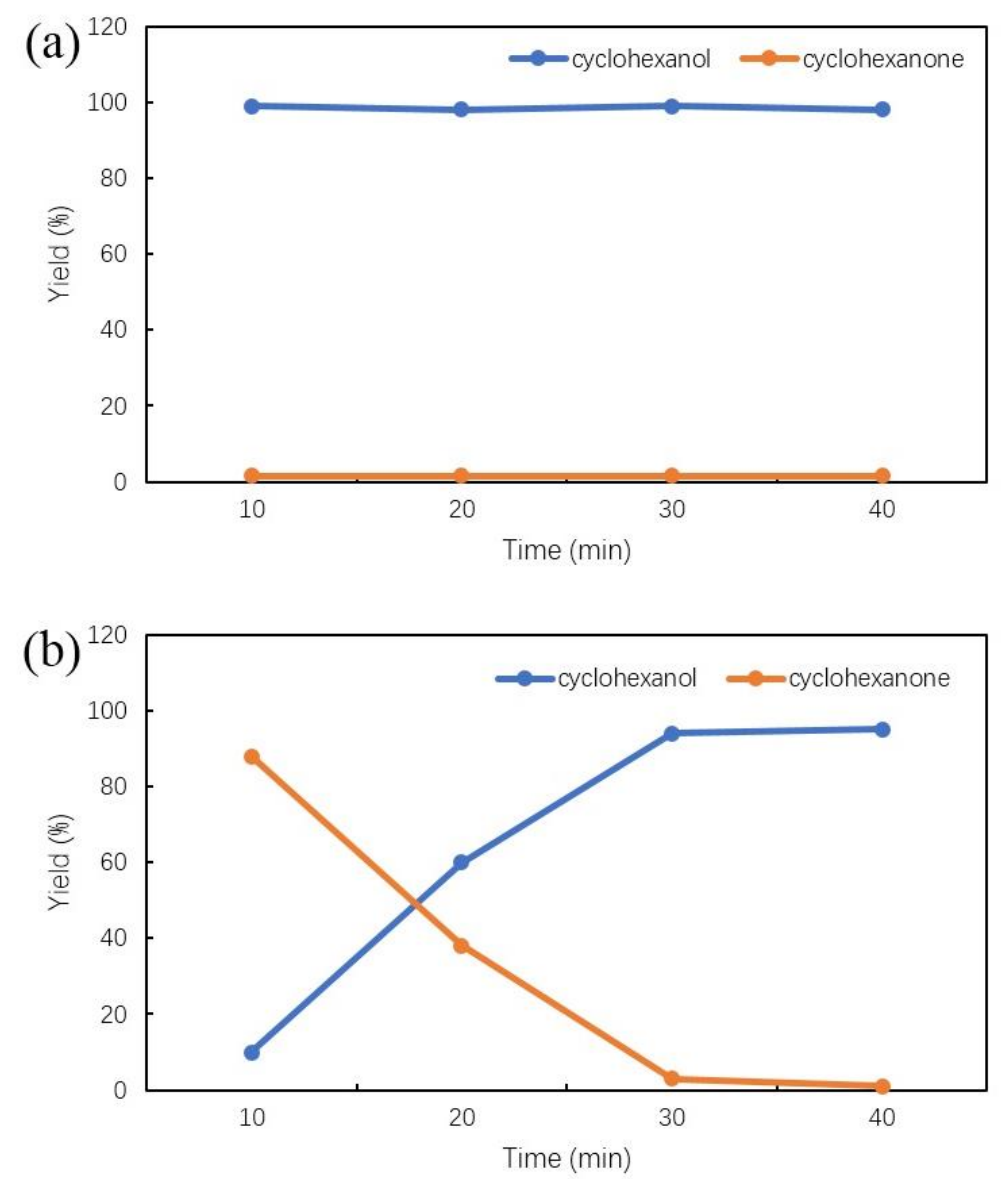

Figure 5. Time course of the yield of cyclohexanol carried out in the transfer hydrogenation (a). Time course of the yield of cyclohexanone carried out in the transfer hydrogenation (b).<smiles>CC(C)OCc1ccc(O)cc1</smiles>

catalyst surface

i<smiles>CC1C=CC=CC(O)C1C</smiles>

catalyst surface

iv

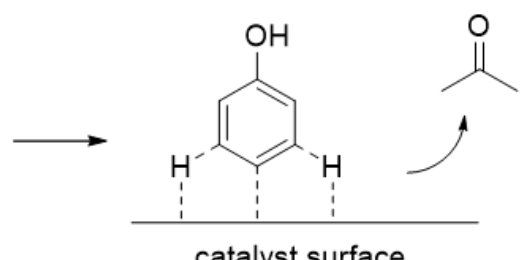

ii

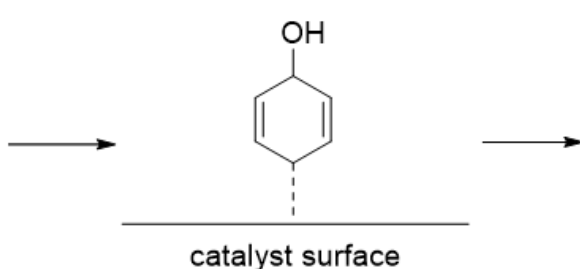

iii

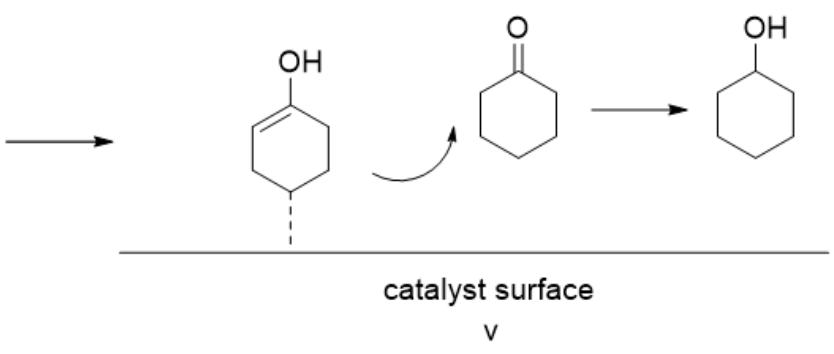

Figure 6. Catalytic pathway in the transfer hydrogenation of phenol.

In addition, the Ni/CNT catalyst could be magnetically recovered after a simple process (washing with isopropanol and dried over $105^{\circ} \mathrm{C}$ ) for the subsequent recycling tests. The recycling tests for the $\mathrm{Ni} / \mathrm{CNT}$ catalyst in the transfer hydrogenation of phenol under the optimal reaction condition 
was subsequently evaluated. Ni/CNT maintained its activity for four succeeding runs, and no obvious decrease in cyclohexanol yield was observed, suggesting the good ability of the catalyst (Figure 7b).

(a)

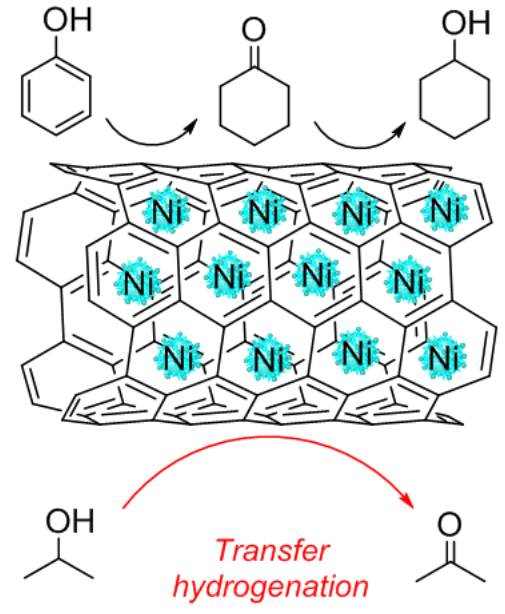

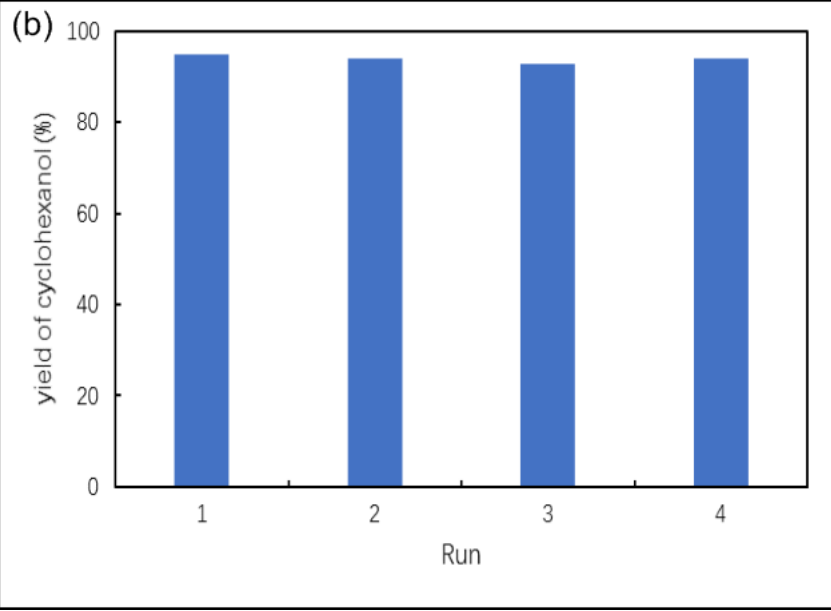

Figure 7. (a) Possible catalytic pathway in the transfer hydrogenation of phenol. (b) Result of recycling tests for Ni/CNT catalyst in the transfer hydrogenation of phenol.

\title{
3. Conclusions
}

In this paper, phenol was effectively hydrogenated to cyclohexanol by $20 \% \mathrm{Ni} / \mathrm{CNT}$ catalyst under a mild condition $\left(220^{\circ} \mathrm{C}, 60 \mathrm{~min}\right)$ using isopropanol as the hydrogen-donor solvent. The Ni/CNT catalyst not only had an excellent ability to catalyze the transfer hydrogenolytic cleavage of phenol and diverse phenol derivatives but also could be easily recovered magnetically from the reaction process for the next four recycling tests. Four succeeding recycling tests in the transfer hydrogenation of phenol proved the good stability of the Ni/CNT catalyst. The possible mechanism for the hydrogenation of phenol suggested that the possible pathway might proceed via the formation of cyclohexanone. This work will inspire various studies on the hydrogenation process in the absence of additional hydrogen.

Author Contributions: Conceptualization, M.Z. and J.J.; methodology, M.Z.; software, J.J.; validation, M.Z., B.K.S. and J.J.; formal analysis, C.C.; investigation, C.C.; resources, P.L.; data curation, P.L.; writing-original draft preparation, C.C.; writing-review and editing, M.Z.; visualization, M.Z.; supervision, J.J.; project administration, M.Z.; funding acquisition, M.Z. All authors have read and agreed to the published version of the manuscript.

Funding: This research was funded by the Fundamental Research Funds of CAF, grant number CAFYBB2018QB007 and the National Natural Science Foundation of China, grant number 31700645.

Acknowledgments: Authors are grateful for the financial support from the Fundamental Research Funds of CAF (No. CAFYBB2018QB007) and the National Natural Science Foundation of China (31700645).

Conflicts of Interest: The authors declare no conflict of interest.

\author{
Abbreviations \\ CNT Carbon nanotube \\ ICP Inductive Coupled Plasma Emission Spectrometer \\ XRD Powder X-ray diffraction \\ XPS X-Ray photoelectron spectroscopy \\ TEM Transmission electron microscopy \\ BET Brunauer- Emmett- Teller \\ GC/MS Gas Chromatograph/Mass Spectrometer
}




\section{References}

1. Xiang, Y.; Ma, L.; Lu, C.; Zhang, Q.; Li, X. Aqueous system for the improved hydrogenation of phenol and its derivatives. Green Chem. 2008, 10, 939-943. [CrossRef]

2. Xiang, Y.; Kong, L.; Xie, P.; Xu, T.; Wang, J.; Li, X. Carbon nanotubes and activated carbons supported catalysts for phenol in situ hydrogenation: Hydrophobic/hydrophilic effect. Ind. Eng. Chem. Res. 2014, 53, 2197-2203. [CrossRef]

3. Porwal, G.; Gupta, S.; Sreedhala, S.; Elizabeth, J.; Khan, T.S.; Haider, M.A.; Vinod, C.P. Mechanistic insights into the pathways of phenol hydrogenation on Pd nanostructures. ACS Sustain. Chem. Eng. 2019, 7, 17126-17136. [CrossRef]

4. Song, Z.; Ren, D.; Wang, T.; Jin, F.; Jiang, Q.; Huo, Z. Highly selective hydrothermal production of cyclohexanol from biomass-derived cyclohexanone over Cu powder. Catal. Today 2016, 274, 94-98. [CrossRef]

5. Sikhwivhilu, L.M.; Coville, N.J.; Naresh, D.; Chary, K.V.; Vishwanathan, V. Nanotubular titanate supported palladium catalysts: The influence of structure and morphology on phenol hydrogenation activity. Appl. Catal. A Gen. 2007, 324, 52-61. [CrossRef]

6. Wang, L.; Zhang, Y.; Du, R.; Yuan, H.; Wang, Y.; Yao, J.; Li, H. Selective one-step aerobic oxidation of cyclohexane to $\epsilon$-caprolactone mediated by N-hydroxyphthalimide (NHPI). ChemCatChem 2019, 11, 2260-2264. [CrossRef]

7. Alazman, A.; Belic, D.; Alotaibi, A.; Kozhevnikova, E.F.; Kozhevnikov, I.V. Isomerization of cyclohexane over bifunctional Pt-, Au-, and PtAu-heteropoly acid Catalysts. ACS Catal. 2019, 9, 5063-5073. [CrossRef]

8. Kim, A.R.; Ahn, S.; Yoon, T.U.; Notestein, J.M.; Farha, O.K.; Bae, Y.S. Fast cyclohexane oxidation under mild reaction conditions through a controlled creation of Redox-active Fe (II/III) Sites in a Metal-organic Framework. ChemCatChem 2019, 11, 5650-5656. [CrossRef]

9. Chary, K.V.; Naresh, D.; Vishwanathan, V.; Sadakane, M.; Ueda, W. Vapour phase hydrogenation of phenol over Pd/C catalysts: A relationship between dispersion, metal area and hydrogenation activity. Catal. Commun. 2007, 8, 471-477. [CrossRef]

10. Nelson, N.C.; Manzano, J.S.; Sadow, A.D.; Overbury, S.H.; Slowing, I.I. Selective hydrogenation of phenol catalyzed by palladium on high-surface-area ceria at room temperature and ambient pressure. ACS Catal. 2015, 5, 2051-2061. [CrossRef]

11. Zhang, X.; Du, Y.; Jiang, H.; Liu, Y.; Chen, R. Insights into the stability of Pd/CN catalyst in liquid phase hydrogenation of phenol to cyclohexanone: Role of solvent. Catal. Lett. 2019, 149, 1-10. [CrossRef]

12. Liu, T.; Zhou, H.; Han, B.; Gu, Y.; Li, S.; Zheng, J.; Zhong, X.; Zhuang, G.L.; Wang, J.G. Enhanced selectivity of phenol hydrogenation in low-pressure $\mathrm{CO}_{2}$ over supported Pd catalysts. ACS Sustain. Chem. Eng. 2017, 5, 11628-11636. [CrossRef]

13. Sanyal, U.; Song, Y.; Singh, N.; Fulton, J.L.; Herranz, J.; Jentys, A.; Gutiérrez, O.Y.; Lercher, J.A. Structure sensitivity in hydrogenation reactions on $\mathrm{Pt} / \mathrm{C}$ in aqueous-phase. ChemCatChem 2019, 11, 575-582. [CrossRef]

14. Singh, N.; Lee, M.S.; Akhade, S.A.; Cheng, G.; Camaioni, D.M.; Gutiérrez, O.Y.; Glezakou, V.A.; Rousseau, R.; Lercher, J.A.; Campbell, C.T. Impact of $\mathrm{pH}$ on aqueous-phase phenol hydrogenation catalyzed by carbon-supported Pt and Rh. ACS Catal. 2018, 9, 1120-1128. [CrossRef]

15. Wang, L.; Zhang, J.; Yi, X.; Zheng, A.; Deng, F.; Chen, C.; Ji, Y.; Liu, F.; Meng, X.; Xiao, F.S. Mesoporous ZSM-5 zeolite-supported Ru nanoparticles as highly efficient catalysts for upgrading phenolic biomolecules. ACS Catal. 2015, 5, 2727-2734. [CrossRef]

16. Nakagawa, Y.; Ishikawa, M.; Tamura, M.; Tomishige, K. Selective production of cyclohexanol and methanol from guaiacol over Ru catalyst combined with MgO. Green Chem. 2014, 16, 2197-2203. [CrossRef]

17. Martinez-Espinar, F.; Blondeau, P.; Nolis, P.; Chaudret, B.; Claver, C.; Castillón, S.; Godard, C. NHC-stabilised Rh nanoparticles: Surface study and application in the catalytic hydrogenation of aromatic substrates. J. Catal. 2017, 354, 113-127. [CrossRef]

18. Kinoshita, A.; Nakanishi, K.; Yagi, R.; Tanaka, A.; Hashimoto, K.; Kominami, H. Hydrogen-free ring hydrogenation of phenol to cyclohexanol over a rhodium-loaded titanium (IV) oxide photocatalyst. Appl. Catal. A Gen. 2019, 578, 83-88. [CrossRef]

19. Wang, Y.; Yao, J.; Li, H.; Su, D.; Antonietti, M. Highly selective hydrogenation of phenol and derivatives over a Pd@carbon nitride catalyst in aqueous media. J. Am. Chem. Soc. 2011, 133, 2362-2365. [CrossRef] 
20. Zhao, C.; Song, W.; Lercher, J.A. Aqueous phase hydroalkylation and hydrodeoxygenation of phenol by dual functional catalysts comprised of Pd/C and H/La-BEA. ACS Catal. 2012, 2, 2714-2723. [CrossRef]

21. Li, Z.; Liu, J.; Xia, C.; Li, F. Nitrogen-functionalized ordered mesoporous carbons as multifunctional supports of ultrasmall Pd nanoparticles for hydrogenation of phenol. ACS Catal. 2013, 3, 2440-2448. [CrossRef]

22. Galkin, M.V.; Sawadjoon, S.; Rohde, V.; Dawange, M.; Samec, J.S. Mild Heterogeneous Palladium-Catalyzed Cleavage of $\beta-\mathrm{O}-4^{\prime}$-Ether Linkages of Lignin Model Compounds and Native Lignin in Air. ChemCatChem 2014, 6, 179-184. [CrossRef]

23. Paone, E.; Espro, C.; Pietropaolo, R.; Mauriello, F. Selective arene production from transfer hydrogenolysis of benzyl phenyl ether promoted by a co-precipitated $\mathrm{Pd} / \mathrm{Fe}_{3} \mathrm{O}_{4}$ catalyst. Catal. Sci. Technol. 2016, 6, 7937-7941. [CrossRef]

24. Wu, H.; Song, J.; Xie, C.; Wu, C.; Chen, C.; Han, B. Efficient and mild transfer hydrogenolytic cleavage of aromatic ether bonds in lignin-derived compounds over Ru/C. ACS Sustain. Chem. Eng. 2018, 6, $2872-2877$. [CrossRef]

25. Zhang, Q.; Li, H.; Gao, P.; Wang, L. PVP-NiB amorphous catalyst for selective hydrogenation of phenol and its derivatives. Chin. J. Catal. 2014, 35, 1793-1799. [CrossRef]

26. Gilkey, M.J.; Xu, B. Heterogeneous transfer hydrogenation as an effective pathway in biomass upgrading. ACS Catal. 2016, 6, 1420-1436. [CrossRef]

27. Croston, M.; Langston, J.; Sangoi, R.; Santhanam, K.S.V. Catalytic oxidation of p-toluidine at multiwalled functionalized carbon nanotubes. Int. J. Nanosci. 2002, 1, 277-283. [CrossRef]

28. Croston, M.; Langston, J.; Takacs, G.; Morrill, T.C.; Miri, M.; Santhanam, K.S.V.; Ajayan, P. Conversion of aniline to azobenzene at functionalized carbon nanotubes: A possible case of a nanodimensional reaction. Int. J. Nanosci. 2002, 1, 285-293. [CrossRef]

29. Gordon, M.; Santhanam, K.S.V. High product yield in a narrow column configuration of carbon nanotubes: A Pathway for nanosynthetic machine. Proc. Electrochem. Soc. 2003, 13, 285-288.

30. Zhou, M.; Tian, L.; Niu, L.; Li, C.; Xiao, G.; Xiao, R. Upgrading of liquid fuel from fast pyrolysis of biomass over modified Ni/CNT catalysts. Fuel Process. Technol. 2014, 126, 12-18. [CrossRef]

31. Zhou, M.; Zhu, H.; Niu, L.; Xiao, G.; Xiao, R. Catalytic hydroprocessing of furfural to cyclopentanol over $\mathrm{Ni} / \mathrm{CNTs}$ catalysts: Model reaction for upgrading of bio-oil. Catal. Lett. 2014, 144, 235-241. [CrossRef]

32. Zhang, J.; Chen, C.; Yan, W.; Duan, F.; Zhang, B.; Gao, Z.; Qin, Y. Ni nanoparticles supported on CNTs with excellent activity produced by atomic layer deposition for hydrogen generation from the hydrolysis of ammonia borane. Catal. Sci. Technol. 2016, 6, 2112-2119. [CrossRef]

33. Li, G.; Han, J.; Wang, H.; Zhu, X.; Ge, Q. Role of dissociation of phenol in its selective hydrogenation on Pt (111) and Pd (111). ACS Catal. 2015, 5, 2009-2016. [CrossRef]

34. Song, Y.; Chia, S.H.; Sanyal, U.; Gutiérrez, O.Y.; Lercher, J.A. Integrated catalytic and electrocatalytic conversion of substituted phenols and diaryl ethers. J. Catal. 2016, 344, 263-272. [CrossRef] 